Vol. 3, No. 02; 2020

ISSN: 2581-4664

\title{
COOPERATIVE MEMBERSHIP AND MULTIDIMENSIONAL POVERTY AMONG POULTRY FARMING HOUSEHOLDS IN SOUTHWEST NIGERIA, EVIDENCE FROM OYO STATE: AN ALKIRE-FOSTER ANALYSIS AND IMPACT MEASUREMENT APPROACH
}

\author{
Popoola, David Prince** and Obi-Egbedi, Ogheneruemu* \\ ** Popooladavidp@gmail.com, +2347034355030, \\ *gheneobi@gmail.com, +2348034751635 \\ Department of Agricultural economics, Faculty of Agriculture. University of Ibadan
}

http://doi.org/10.35409/IJBMER.2020.3167

\begin{abstract}
This study was conducted in Southwest Nigeria to examine the impact of cooperative membership on the poverty status of poultry farming households in Southwest Nigeria, using the multidimensional approach while controlling for selection bias. This can enhance understanding for more impactful policy making. A multistage sampling technique was employed in the random data collection from 210 poultry farmers; 101 Cooperators and 109 Noncooperators from four local government areas, using well-structured questionnaires. Descriptive statistics, Alkire-Foster multidimensional poverty indices, Treatment effect models of the propensity score matching, inverse probability weighing and nearest neighbour matching algorithms are employed in data analysis. The multidimensional poverty index, incidence of deprivation across nine of the various ten welfare indicators with the aggregated average intensity of deprivations was found to be significantly higher among the Noncooperator poultry farming household category when compared to their Noncooperator counterparts. Also, Cooperative societies apart from its poverty reduction impact on the Cooperator, was also found to have significant negative impact on multidimensional poverty status among Noncooperator poultry farming households. Multipurpose cooperatives was found to reduce poverty more than other types of cooperatives. Finding based policy options were proffered
\end{abstract}

Keyword: Cooperative membership, Multidimensional poverty, Nigeria, Alkire-Foster multidimensional poverty measures, Welfare, Treatment effects.

\section{INTRODUCTION}

Poverty has been a global issue of many dimensions and complexities, a longstanding quagmire among the estimated world's 6.9 billion people with varying rate of occurrence from one part of the world to another. Although, world's extreme poverty of below US\$2.0/person per day has reduced significantly from $18.6 \%$ (2008) to $14.5 \%$ (2011) and 11.0\% (2013), indicating a shrinking global poverty trend however, high incidence of poverty is widespread in the Sub-Saharan Africa and South Asia relative to other developing regions, accounting for about $80 \%$ of the global poor of which about $50.7 \%$ of the global poor lives in sub-Saharan Africa, especially in Nigeria (World 


\section{International Journal of Business Management and Economic Review}

Vol. 3, No. 02; 2020

ISSN: 2581-4664

Bank 2015;2016) where Agriculture has been the locus of poverty and about 70\% of the population are directly or indirectly dependent on agriculture for their livelihood (NBS 2012;2014). Also, the welfare of farmers remains generally low due to fall in productivity, attributable to menace of low agricultural technology, food insecurity and low income (Amao and Awoyemi, 2008). The livestock sector can however serve as a significant source of livelihoods, and a potential pathway out of poverty (IFAD, 2011), wherein the largest share of the poor among the 900 million peopleresides in rural areas, and half of these poor rear livestock (World Bank, 2016; Robinson, 2011).

It is notable that, of the total GDP accrued to the Agricultural industry within the Nigeria's economy, the various sub-sector contributions includes; Crop (87.2\%), Livestock (9.0\%), Fishery $(3.0 \%)$ and Forestry (1.2\%) respectively, where the livestock sector contributes relatively low (FAO 2016, NBS 2015). The Nigerian poultry industry is characterized by small-holder farmers rearing below 1000 birds (Ministry of Agriculture, 2012), employing different production strategies with little available resources resulting to low productivity, production inefficiency and low return to investment hence, poverty.

In an attempt to tackle the challenges facing the sector, willing farmers usually come together, forming a member focused institution where they pool resources together via a jointly owned and democratically controlled enterprise, usually called Cooperative society. Cooperatives serves an important means of poverty reduction, they identify economic opportunities for their members; empower the disadvantaged; secure the poor by converting their individual risks into joint risks; and mediate members' access to assets to earn good living as Cooperatives focuses on its members rather than profit making. There is a widely held consensus among many economic key role actors, including the United Nations (UN), the International Labour Organization (ILO), and the International Co-operative Alliance (ICA) that, the cooperative enterprise is typically suited to addressing all dimensions of reducing poverty and exclusion (ILO; ICA, 2015).

Teklehaimanot et al., (2016) assessed the impact of agricultural marketing cooperative societies in enhancing rural livelihood in India, using the livelihood assets approach, a non-monetary approach. Their results showed a declining poverty and increasing income as a result of the marketing society in which a significant change was found in habitat, social, income and food security among marketing society members. Tolulope et al. (2016) evaluated the poverty situation mong 172 farming households in selected areas in Ibadan, Oyo state. The incidence of poverty was $50.58 \%$ and the average intensity of poverty was $48.7 \%$, the Multidimensional Poverty Index (MPI) for the sampled households was 0.246. Besides, Oyekale et al., (2006) evaluates the impact of poverty reduction programs on multidimensional poverty in rural Nigeria, using the 2006 core welfare indicator survey (CWIQ) data and Fuzzy set approach. The result shows that the multidimensional poverty for the rural Nigeria is 0.3796 .

However, many of the previous researches on multidimensional poverty did not explore the specific dimensions of deprivation suffered by the poor households, did not control for selection bias where necessary, restricted to estimating income poverty while a little empirical researches relates poultry production and cooperative membership to multidimensional poverty in the study area. This is probably due to scarce methods to link poultry production and cooperative membership to multidimensional poverty. Besides, most impact studies do not capture the potential differences between participants/cooperators and nonparticipants/noncooperators, making it difficult to conclude on the estimation (Rahman 1999; Mendola 2007). Also, little is 


\section{International Journal of Business Management and Economic Review}

Vol. 3, No. 02; 2020

ISSN: 2581-4664

however known about the extent to which cooperative societies have achieved this primary goal among its members in the study area, where there is widespread Poultry production activities as Oyo State has the highest incidence of registered poultry farmers in Nigeria (PAN, FDLPCS, 2007).

Furthermore, the deprivations experienced by the farmers are more than just income poverty. Poverty is a multi-dimensional phenomenon for which causes, conditions, and consequences remain difficult to directly identify, and quantify hence, requires a cross dimensional approach in its measurement. This study thus attempts to evaluate the impact of Cooperative membership on the poverty status of poultry farmers in Oyo state. Specifically, the multidimensional poverty status of poultry farmers was estimated and profiled across cooperatives. The impact of cooperative membership on the multidimensional poverty status of poultry farming households was also assessed.

\section{MATERIALS AND METHODS Study area/ Data Collection}

This study was carried out in Oyo State, South western Nigeria. The state's land area covers 35,743 $\mathrm{km} 2$ situated within latitude 3 and $5^{\circ} \mathrm{N}$; between longitude $7^{\circ} \mathrm{E}$ and $9.3^{\circ} \mathrm{E}$, characterized by intensive rearing of exotic breeds of cockerels, layers and broiler birds which is a widespread activities in the study areas. Four (4) Agricultural Development Project (ADP) zones exist in the state as categorized by the Oyo state Agricultural Development Project (OYSADEP) which includes; Ibadan/Ibarapa, Oyo, Ogbomoso and Saki zones, with varying degrees of poultry production activities.

Data related to the socio-economic characteristics alongside farm Production activities of the poultry farmers among others was collected, in addition to data on education, living standard and health of farmers were collected from the poultry farmers in the study area, using a multistage sampling technique.

The first stage involved random selection of two agricultural zones which are Ibadan/Ibarapa and Oyo Agricultural zones from the four Agricultural Zones in Oyo state. The second stage involved a random selection of three local government areas under the Oyo agricultural zone and one Local government in Ibadan/Ibarapa Zone due to the relatively larger poultry production activities being carried out at Oyo agricultural zone compared to Ibadan/Ibarapa. The third stage involved a random selection of ten villages under Ido Local government area and three villages per Afijio, Oyo central, and Oyo west local government areas, from which 240 poultry farmers were randomly selected in the final stage. Data collection was between June-August, 2017 with the supports of three volunteer field enumerators. Only 210 samples were utilized in the analysis due to nonresponse and non-return of questionnaires.

The Statistics and Data (STATA) '14 analytical tool was used in data analysis.

\section{Analytical techniques}

\section{a. Alkire and Foster Measure (AFM) for estimating multidimensional poverty}

The Alkire Foster multidimensional measures distinguishes 'the poor and nonpoor' by considering the range of deprivations they suffer. The methodology includes two steps: considering the range of deprivations they suffer, and an aggregation to generates an intuitive set of poverty measures $(\mathrm{M} \alpha)$ that can be broken down to target the poor people and the dimensions in which they are most 


\section{International Journal of Business Management and Economic Review}

Vol. 3, No. 02; 2020

ISSN: 2581-4664

deprived.

\section{Dimensions, indicators, cutoffs, and weights}

A vector $\mathrm{w}=(\mathrm{w} 1, \ldots, \mathrm{wd})$ of weights or deprivation values is used to indicate the relative importance of the different deprivations and all weights sum up to the number of dimensions " $d$ ". The vector " $C$ " of deprivation counts is compared against a cut-off " $\mathrm{k}$ " to identify the poor. The variable k reflects the sum of weighted indicators in which a household must be deprived in order to be considered multidimensionally poor. " $\mathrm{k}$ " is inversely proportional to incidence of poverty $(\mathrm{H} \neg \neg \neg 0)$ while the intensity or breadth of deprivations (A0) in any poor household increases. We report three levels for $\mathrm{k} ; \mathrm{k}=4, \mathrm{k}=3$ and $\mathrm{k}=2$ for comparison.

When $\mathrm{k}=3$, a household has to be deprived in at least the equivalence of $30 \%$ of the weighted indicators in order to be considered multidimensionally poor, implying that if $\mathrm{Cis} 33.3 \%$ or greater, that household is multidimensionally poor. This is decomposable into six asset indicators, or two health, or education indicators. If we choose instead cutoff value $\mathrm{k}=2$ then all poor households must be deprived in at least $20 \%$ of the indicators (chronic poverty). The maximum score is $100 \%$; with each dimension equally weighted (thus the maximum score in each dimension is $33.3 \%$ ). Each indicator within a dimension is also equally weighted. A poverty cut-off $\mathrm{k}$ satisfying $0<\mathrm{k} \leq$ $\mathrm{C}$ is used to determine whether a farmer has sufficient deprivations to be considered poor or otherwise. Specifically, the deprivation headcount (Ho) and the dimension adjusted head count (Mo) model following Alkire and Foster, (2011), are given as;

$$
\begin{aligned}
& \mathrm{H}_{\mathrm{o}}(\mathrm{X} ; \mathrm{k} ; \mathrm{Z}) \equiv \frac{1}{N} \sum_{n=1}^{N} \mathrm{I}(\mathrm{Cn} \geq \mathrm{k})=\frac{\mathrm{q}}{\mathrm{N}} \ldots . \\
& \mathrm{A}(\mathrm{X} ; \mathrm{k} ; \mathrm{Z}) \equiv \frac{\sum_{n=1}^{N} \mathrm{I}(\mathrm{Cn} \geq \mathrm{k}) \mathrm{Cn}}{\mathrm{q}}=\frac{\sum_{1}^{q} \mathrm{c}}{q} \ldots \ldots \ldots . \\
& \mathrm{M}_{\mathrm{o}} \equiv\left[\frac{1}{N} \sum_{n=1}^{N} \mathrm{I}(\mathrm{Cn} \geq \mathrm{k})\right]\left[\frac{\sum_{1}^{q} \mathrm{c}}{q}\right]=\mathrm{H}_{\mathrm{o}} \times \mathrm{A} \\
& \text { Where: }
\end{aligned}
$$

$\mathrm{Ho}=$ Head Count Ratio, $\mathrm{A}=$ Average intensity of deprivation, $\mathrm{M} 0=$ Multidimensional Poverty Index (MPI), $\mathrm{q}=$ the number of people who are multidimensionally poor, $\mathrm{N}=$ Total population, $\mathrm{C}=$ is the deprivation score that the poor experience, $\mathrm{I}(\mathrm{Cn} \geq \mathrm{k})=$ indicator that takes the value of 1 if the expression in parenthesis is true. Otherwise it takes the value of 0 . Indicators and dimensions chosen were based to a large extent on international standards such as the Sustainable Development Goals. The indicators and cutoffs are summarized in table 1.

Table 1: Dimensions, indicators and weights

\begin{tabular}{|l|l|l|l|l|}
\hline Dimensions & \multicolumn{1}{|c|}{ Indicators } & \multicolumn{1}{|c|}{ Measurements } & $\begin{array}{l}\text { Related } \\
\text { to... }\end{array}$ & Weights \\
\hline Education & $\begin{array}{l}\text { Years of } \\
\text { schooling }\end{array}$ & $\begin{array}{l}\text { Deprived if no household member has } \\
\text { completed 9 years of formal education }\end{array}$ & SDG 4 & $1 / 6$ \\
Child enrolment & $\begin{array}{l}\text { Deprived if any school-aged child is not } \\
\text { attending school in years 1 to 6 }\end{array}$ & SDG 4 & $1 / 6$ \\
\hline $\begin{array}{c}\text { Standard of } \\
\text { Living }\end{array}$ & Electricity & Deprived if the household has no electricity & SDG 7 & $1 / 18$ \\
\hline
\end{tabular}




\section{International Journal of Business Management and Economic Review}

Vol. 3, No. 02; 2020

ISSN: 2581-4664

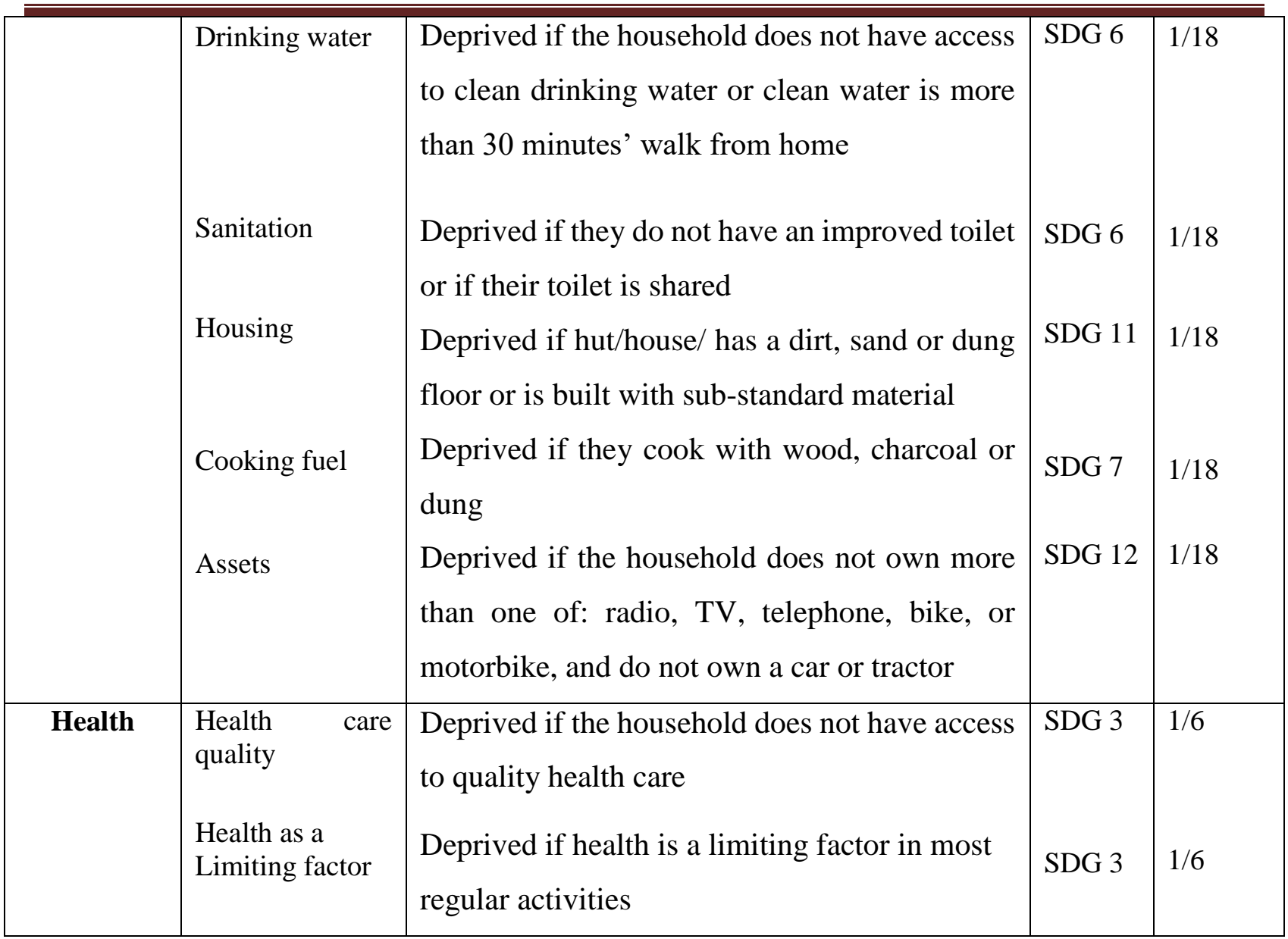

Note: SDG1 is Eradicate Extreme Poverty; SDG2 is Zero Hunger; SDG3 is Good Health and Wellbeing; SDG4 is Quality Education; SDG6 is Clean Water and Sanitation SDG7 is Affordable and clean Energy; SDG11 is Sustainable cities and Communities; SDG12 is Responsible consumption and Production.

Source: (UNDP, 2015; Alkire et al. 2016). 


\section{International Journal of Business Management and Economic Review}

Vol. 3, No. 02; 2020

ISSN: 2581-4664

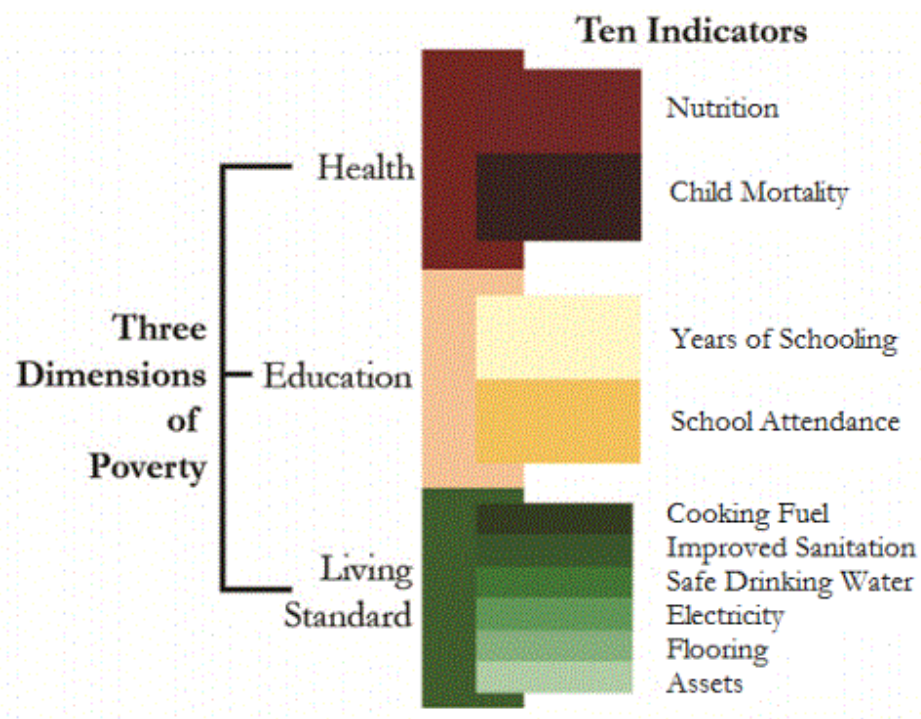

Figure 1: Dimensions and indicators of multidimensional poverty

Source: Alkire et al., (2016).

\section{b. Impact measurement and selection biases control.}

It is worth nothing that a good impact measurement design requires appropriate counterfactual, while controlling for selection bias (Imbens, and Wooldridge, 2009; Dontsop et al., (2011). The nearest neighbour matching, Inverse probability weighing and the propensity score matching methods are employed in the evaluation of impact of cooperative membership on the multidimensional poverty status of poultry farmers.

\section{Propensity score matching (PSM) method.}

This study employs the non-parametric approach. First, the model estimate the propensity score (PS) as the probability of the sampled farmers to be a member of an agricultural cooperative (D). $\mathrm{PS}=\mathrm{P}(\mathrm{D}=1 \mid \mathrm{X})$.

We use a Probit model and include a large set of conditioning factors (Xi) that can explain a possible non-random distribution of cooperative membership in the population:

Where; $\mathrm{X} 1=$ Gender of household head (dummy; Male=1, Female=0), X2 = Marital status (dummy; 1, if married 0, if otherwise), X3 = Level of education of Household head (years), X4 = Highest level of education in the household other than household head's (years), X5= Age of Household Head in years, X6 $=$ Household size, $X 7=$ Dependency ratio, $X 8=$ Farming experience level (in years), X9= Farming as Primary occupation (dummy yes $=1$, otherwise $=0$ ), $\mathrm{X} 10=$ Access to credit (dummy; Yes=1; No=0), X11= Access to infrastructure (dummy; Yes=1; No=0), X12= Primary source of labour (Dummy; Paid labor=1, Family Labor=0), X13= Cooperative membership (dummy; Yes $=1 ; \mathrm{No}=0$ ).

Average treatment effects (ATE) of cooperative membership on multidimensional poverty is estimated. We use the estimated PS to match treated observations or cooperative member households with untreated observations or non-member households. The average treatment effects is estimated as the average difference in the poverty (deprivations) between treated $\mathrm{Y}(1)$, and 
Vol. 3, No. 02; 2020

matched controls $\mathrm{Y}(0)$ as used by Imbens, 2004; Rosenbaum and Rubin, 1983.

$\mathrm{ATE}=\mathrm{E}[\mathrm{Y}(1)-\mathrm{Y}(0)]=\mathrm{E}[\mathrm{Y}(1)]-\mathrm{E}[\mathrm{Y}(0)]$.

$A T \mathrm{E} T=\mathrm{E}[\mathrm{Y}(1)-(\mathrm{Y}(0) \mid \mathrm{W}=1]$

$\mathrm{ATE}=\mathrm{n}^{-1} \sum_{\mathrm{i}=1}^{\mathrm{n}} \frac{\left.\mathrm{D}_{\mathrm{i}}-\mathrm{P}\left(\mathrm{X}_{\mathrm{i}}\right)\right) \mathrm{Y}_{\mathrm{i}}}{\mathrm{P}\left(\mathrm{X}_{\mathrm{i}}\right)\left(1-\mathrm{P}\left(\mathrm{X}_{\mathrm{i}}\right)\right)}$

ATE1 $=n^{-1} \sum_{i=1}^{n} \frac{\left.D_{i}-P\left(X_{i}\right)\right) Y_{i}}{\left(1-P\left(X_{i}\right)\right)}$

$\mathrm{n}=$ sample size,

$\sum_{\mathrm{i}=1}^{\mathrm{n}} \mathrm{D}_{\mathrm{i}}=$ Number of treated,

$\mathrm{P}\left(\mathrm{X}_{\mathrm{i}}\right)=$ consistent estimate of the propensity score evaluated.

\section{Nearest neighbour matching}

Nearest neighbour matching requires a selection and matching each treatment and control units with the closest propensity scores; i.e., the Nearest Neighbour. It generally selects k matched controls for each treated unit (often, $\mathrm{k}=1$ ) Rubin, (1973). The nearest neighbour matching uses a "greedy" algorithm, which cycles through each treated unit one at a time, selecting the available control unit with the smallest distance to the treated unit.

$\|x\| V=\left(x^{\prime} V_{x)^{\frac{1}{2}}}\right.$
$\|z-x\| V \ldots \ldots \ldots$

Considering the set of observed covariates for an individual i, Xi, let eqn. 9 be the normal vector, having positive definite matrix $\mathrm{V}$. We define eqn. 10 as the distance between the vectors $\mathrm{x}$ and $\mathrm{z}$, where $z$ represents the covariate values for a potential match for observation $i$. Let $d M(i)$ be the distance from the covariates for unit $\mathrm{i}, \mathrm{Xi}$, to the Mth nearest match with the opposite treatment. Allowing for the possibility of ties, at this distance fewer than $M$ units are closer to unit $i$ than $\mathrm{dM}(\mathrm{i})$ and at least $\mathrm{M}$ units are as close as $\mathrm{dM}(\mathrm{i})$. Formally, $\mathrm{dM}(\mathrm{i})>0$ is the real number satisfying; $\mathrm{x}^{\prime}$ Vx (Alberto et al., 2004)

$$
\sum_{l: W_{l}=1-W_{i}} 1\left\{\left\|X_{l}-X_{i}\right\|_{V}<d_{M}(i)\right\}<M
$$

and

$$
\sum_{l: W_{l}=1-W_{i}} 1\left\{\left\|X_{l}-X_{i}\right\|_{V} \leq d_{M}(i)\right\} \geq M
$$

Where: $1\{\bullet\}$ is the indicator function, which is equal to one if the expression in brackets is true and zero if otherwise.

Let JM(i) denote the set of indices for the matches for unit $i$ that are at least as close as the Mth match:

$$
\mathcal{J}_{M}(i)=\left\{l=1, \ldots, N \mid W_{l}=1-W_{i},\left\|X_{l}-X_{i}\right\|_{V} \leq d_{M}(i)\right\}
$$

These estimates can be utilized to estimate the average treatment effect for the treated (ATET) as follows; 
Vol. 3, No. 02; 2020

ISSN: 2581-4664

$$
T_{M}^{s m, t}=\frac{1}{N} \sum_{t: W_{i}=1}\left\{Y_{i}-\hat{Y}(0)\right\}=\frac{1}{N} \sum_{t=1}^{N}\left\{W_{i}-\left(1-W_{i}\right) K_{M}(i)\right\} Y_{i}
$$

or the average treatment effect (ATE) for the controls

$$
T_{M}^{s m, c}=\frac{1}{N_{0}} \sum_{t: W_{i}=1}\left\{\hat{Y}(1)-Y_{i}\right\}=\frac{1}{N_{0}} \sum_{i=1}^{N}\left\{W_{i} K_{M}(i)-\left(1-W_{i}\right)\right\} Y_{i}
$$

\section{Inverse probability weighting}

Inverse probability weighting (IPW) estimates the effects, by using means of the observed outcomes weighted by the inverse probability of treatment. The IPW estimators use quasimaximum likelihood (QML) to estimate the parameters of the conditional probability model. The vector of estimating functions is the concatenation of the estimating functions for the effect parameters with the estimating functions for the conditional probability parameters (Cattaneo et al., 2013). The sample estimating functions used by the IPW estimators are;

$$
S_{i p w, i}\left(x_{i}, \hat{\theta}\right)^{\prime}=s_{i p w, e, i}\left(x_{i}, \hat{\theta}, \hat{Y}\right)^{\prime} s_{t m, i}\left(z_{i}, 1, \hat{Y}\right)^{\prime}
$$

The estimating functions Sipw, $(\mathrm{x} i, \theta, \gamma)^{\prime}$ vary over the effect parameter.

\section{RESULTS AND DISCUSSION}

\section{a. Distribution of cooperative membership status among Poultry farmers}

Table 2 shows the distribution of cooperative membership status among the Cooperator poultry farmers in the study area. The result shows that most of the Cooperators (59 \%) belongs to the multipurpose cooperative society, while about $7 \%$ belongs to producer and marketing cooperative societies. The observed relatively higher membership incidence of multipurpose cooperative society can be linked to the multipurpose/ multifaceted benefits it offers its members.

Table 2: Distribution of Cooperators poultry farmers by cooperative type

\begin{tabular}{|lcc|}
\hline \multicolumn{1}{|c}{ Cooperative membership status } & Frequency & Percentage \\
\hline Producer Cooperators & 7 & 6.93 \\
Marketing Cooperators & 7 & 6.93 \\
Consumer Cooperators & 27 & 26.73 \\
Multipurpose Cooperators & 60 & 59.41 \\
Total Cooperators & $\mathbf{1 0 1}$ & $\mathbf{4 8 . 0 9}$ \\
Total Noncooperators & $\mathbf{1 0 9}$ & $\mathbf{5 1 . 9 0}$ \\
Pooled & $\mathbf{2 1 0}$ & $\mathbf{1 0 0 . 0 0}$ \\
\hline
\end{tabular}

Source: Author's field survey data analysis result, 2017

\section{b. Description of demographic and socioeconomic characteristics}

The summary of the demographic and socioeconomic characteristics of the Cooperator and noncooperator poultry farmers is shown in table 3 . The result shows that, about $74 \%$ and $77 \%$ of the Cooperator and Noncooperator poultry farmers are respectively married while the mean age of the Cooperator and noncooperator poultry farmers is 47 years. The modal age group was 41-50 years for both categories of poultry farmers indicating that most of the poultry farmers are within the productive age. This is in consonance with the findings of Adeoti (2014), and Adenuga et al., 


\section{International Journal of Business Management and Economic Review}

Vol. 3, No. 02; 2020

ISSN: 2581-4664

(2016). There exist a significant difference (at $\mathrm{p}<0.005)$ in the mean age of Cooperator and noncooperator poultry farmers. The mean years of farming experience was 11years, while the mean household size is 5 persons per poultry farming households. Regarding access to infrastructure, more than $81 \%$ of the poultry farmers in the study area are deprived of access to electricity on their poultry farm while only about $18 \%$ does. Also, more than $76 \%$ of the poultry farmers in the study area do not have access to extension services while only about $24 \%$ have access to extension services. This is most likely due to shortage of extension agents in the study area.

Table 3: Description of Socioeconomic Characteristics of Poultry Farmers by Cooperative membership status

\begin{tabular}{|c|c|c|c|}
\hline Characteristics & Cooperators $\mathrm{N}=101$ & \%Non-Cooperators $\mathrm{N}=109$ & \%Pooled N=210 \\
\hline \multicolumn{4}{|l|}{ Gender } \\
\hline Male & $88(87.05)$ & $92(84.40)$ & $180(85.71)$ \\
\hline Female & $13(12.87)$ & $17(15.60)$ & $30(14.29)$ \\
\hline \multicolumn{4}{|l|}{ Marital status } \\
\hline Married & $75(74.26)$ & $84(77.06)$ & $159(75.71)$ \\
\hline Single & $26(25.74)$ & $25(22.94)$ & $51(24.29)$ \\
\hline Mean Age & $49.14(1.16)$ & $44.67(1.18)$ & $\begin{array}{l}46.82(0.84) \\
\mathrm{P}=0.0036^{* * *}\end{array}$ \\
\hline $\begin{array}{l}\text { Mean years of formal } \\
\text { education }\end{array}$ & $18.27(0.39)$ & $17.45(0.57)$ & $\begin{array}{l}17.45(0.36) \\
\mathrm{P}=0.47\end{array}$ \\
\hline $\begin{array}{l}\text { Mean Years of Farming } \\
\text { Experience }\end{array}$ & $12.14(1.17)$ & $10.17(1.13)$ & $\begin{array}{l}11.08(0.39) \\
\mathrm{P}=0.3009\end{array}$ \\
\hline Mean Household Size & $4.69(0.22)$ & $4.28(0.21)$ & $\begin{array}{l}4.49(0.33) \\
P=0.2216\end{array}$ \\
\hline \multicolumn{4}{|l|}{ Access to Infrastructure } \\
\hline Yes & $23(22.77)$ & $15(13.76)$ & $38(18.10)$ \\
\hline No & $77(77.23)$ & $94(86.24)$ & $172(81.90)$ \\
\hline \multicolumn{4}{|l|}{ Access to extension agent } \\
\hline Yes & $30(29.70)$ & $20(18.35)$ & $50(23.81)$ \\
\hline No & $71(70.30)$ & $89(81.65)$ & $160(76.19)$ \\
\hline \multicolumn{4}{|l|}{ Labour Source } \\
\hline Family & $27(26.73)$ & $36(33.03)$ & $63(30.00)$ \\
\hline Paid & $43(42.57)$ & $59(54.13)$ & $102(48.57)$ \\
\hline Both & $31(30.69)$ & $14(12.84)$ & $45(21.43)$ \\
\hline
\end{tabular}

Source: Author's field survey data analysis result, 2017. Robust standard deviation Parenthesized. Level of Sig $* * * \mathrm{P} \leq 0.01, * * \mathrm{P} \leq 0.05, * \mathrm{P} \leq 0.10$

c. Multidimensional poverty status

Incidence of deprivation

Table 4 shows the cross tabulated incidence of deprivation among the Cooperator and Noncooperator poultry farmers in the study area. From the result, the highest incidence of 
Vol. 3, No. 02; 2020

ISSN: 2581-4664

deprivation occurs in the standard of living dimension manifesting in form of poor access to potable water as about $54 \%$ of the poultry farmers are deprived of access to clean water, where $56 \%$ and $53 \%$ are Cooperator and Noncooperator respectively. Also, about $36 \%$ are deprived in asset acquisition where $42 \%$ and $30 \%$ are Noncooperator and Cooperator respectively. Furthermore, about $26 \%$ of the poultry farmers in the study area lack access to quality healthcare. Regarding Child's school enrolment, only $9 \%$ of the poultry farming households are deprived. This low incidence of deprivation in the education dimension could indicate the success of the Universal Basic Education (UBE) programme of the government as part of the effort to achieve the sustainable development goal through free and compulsory basic education programme.

Table 4: Cross tabulation of the incidence of Deprivation across indicators by cooperative membership status.

\begin{tabular}{|c|c|c|c|c|c|c|}
\hline \multirow{2}{*}{$\begin{array}{c}\begin{array}{c}\text { Dimensions and } \\
\text { Indicators }\end{array} \\
\text { Education }\end{array}$} & \multicolumn{2}{|c|}{ Cooperators $\mathrm{N}=101$} & \multicolumn{2}{|c|}{$\begin{array}{c}\text { Non-Cooperators } \\
\mathbf{N}=\mathbf{1 1 0} \\
\end{array}$} & \multicolumn{2}{|c|}{ Pooled N=210 } \\
\hline & Freq. & Percentage & Freq. & Percentage & Freq. & Percentage \\
\hline \multicolumn{7}{|l|}{ enrolment } \\
\hline Child & 6 & 5.94 & 14 & 12.84 & 20 & 9.52 \\
\hline \multicolumn{6}{|l|}{ Health } & \\
\hline Quality Health & 23 & 22.77 & 32 & 29.36 & 55 & 26.19 \\
\hline \multicolumn{7}{|l|}{ Care } \\
\hline Sickness & 16 & 15.84 & 8 & 7.34 & 24 & 11.43 \\
\hline \multicolumn{6}{|l|}{ Living } & \\
\hline Electricity & 18 & 17.82 & 33 & 30.28 & 51 & 24.29 \\
\hline Clean Water & 57 & 56.44 & 58 & 53.21 & 115 & 54.76 \\
\hline Sanitation & 19 & 18.81 & 25 & 22.94 & 44 & 20.95 \\
\hline Housing & 5 & 4.95 & 17 & 15.60 & 22 & 10.48 \\
\hline Cooking fuel & 14 & 13.86 & 33 & 30.28 & 47 & 22.38 \\
\hline Asset & 30 & 29.70 & 46 & 42.0 & 76 & 36.19 \\
\hline
\end{tabular}

Source: Field Survey data analysis result, 2017. 
Vol. 3, No. 02; 2020

ISSN: 2581-4664

\section{d. Multidimensional poverty status across cutoffs $(k=2, k=2, k=3)$}

The estimates of the respondents' poverty index at each level of deprivation cut-offs; " $\mathrm{K}=2$, $\mathrm{K}=3, \mathrm{~K}=4$ " are shown on Table 5 . The results reveal that when the poverty line is set at " $\mathrm{k}=2$ "; about $35 \%$ of the poultry farming households are chronically poor of which $39 \%$ and $31 \%$ are respectively Noncooperator and Cooperator, respectively suffering from $39.1 \%$ and $32.9 \%$ of the averagely weighted indicators while at " $\mathrm{k}=3$ ", about $20 \%$ are multidimensionally poor of which $22.0 \%$ are Noncooperators and $17 \% \%$ are Cooperators, respectively suffering from $50.7 \%$ and $38.9 \%$ averagely weighted indicators.

Table 5 also shows that the deprivation status of the Noncooperator poultry farmers is higher than that of their Cooperators counterpart at each level of K. The pooled MPI of the poultry farmers are $0.126,0.091$, and 0.062 at $\mathrm{K}=20 \%, \mathrm{~K}=30 \%$ and $\mathrm{K}=40 \%$ respectively. Also, the relationship of poverty incidence (H0), and average intensity of deprivation (A) with " $\mathrm{k}$ " is inverse and direct respectively such that; the higher the level of " $\mathrm{k}$ ", the lower the poverty incidence and the higher the average intensity of deprivation and vice versa such that deprivation incidence when $\mathrm{K}=20 \%>\mathrm{K}=30 \%>\mathrm{K}=40 \%$ and the average intensity of deprivation when $\mathrm{K}=2<\mathrm{K}=3<\mathrm{K}=4$. This is in consonance with the results of Adeoti and Adeoti (2014) and Adenuga et al. (2015).

Table 5: Multidimensional poverty status at $20 \%, 30 \%$, and $40 \%$ deprivation cut-offs

\begin{tabular}{|lccc|}
\hline Parameters & $\begin{array}{c}\text { Cooperators } \\
\mathbf{N = 1 0 1}\end{array}$ & $\begin{array}{c}\text { Noncooperators } \\
\mathbf{N = 1 0 9}\end{array}$ & Pooled N=210 \\
\hline When K=4 & 0.069 & 0.156 & 0.114 \\
Multidimensional Headcount $\left(\mathrm{H}_{0}\right)$ & 0.484 & 0.571 & 0.546 \\
Intensity of Deprivation (A) & 0.033 & 0.089 & 0.062 \\
Multidimensional Poverty Index $\left(\mathrm{M}_{0}\right)$ & & & \\
When K=3 & 0.168 & 0.220 & 0.195 \\
Multidimensional Headcount $\left(\mathrm{H}_{0}\right)$ & 0.389 & 0.507 & 0.466 \\
Intensity of Deprivation (A) & 0.065 & 0.112 & 0.091 \\
Multidimensional Poverty Index $\left(\mathrm{M}_{0}\right)$ & & & 0.348 \\
When K=2 & 0.307 & 0.385 & 0.365 \\
Multidimensional Headcount $\left(\mathrm{H}_{0}\right)$ & 0.329 & 0.391 & 0.126 \\
Intensity of Deprivation (A) & 0.101 & 0.151 & \\
Multidimensional Poverty Index $\left(\mathrm{M}_{0}\right)$ & 2017. & & \\
\hline
\end{tabular}

Source: Field Survey data analysis result, 2017.

\section{e. Multidimensional poverty status across cooperative societies}

Table 6 shows the multidimensional poverty status across the cooperative societies. The result shows that, about $29 \%, 19 \%, 15 \%$, and $14 \%$ respectively of the producers, consumers, multipurpose and marketing Cooperator poultry farmers are living below the poverty line while 


\section{International Journal of Business Management and Economic Review}

Vol. 3, No. 02; 2020

ISSN: 2581-4664

respectively deprived in 58\%, 41\%, 40\%, and 33\% of the averagely weighted indicator, $19 \%$ of the Consumer Cooperator poultry farmers fell below the poverty line and are deprived in $41 \%$ of the averagely weighted indicators. The comparatively low incidence of deprivation observed among the marketing cooperative poultry farmers is linkable to the relatively higher market access/advantage that they are able to harness via their cooperative society hence, bringing about increased sales, which transcends to increased revenue and consequently lower poverty while the highest poverty incidence is observed amidst the producer Cooperators.

Table 6: Multidimensional poverty status of the poultry farmers across the cooperative types at $\mathrm{K}=\mathbf{3 0 \%}$

\begin{tabular}{|c|c|c|c|c|c|c|}
\hline Parameters & \multicolumn{5}{|c|}{ Cooperators } & Noncooperators \\
\hline At $K=30 \%$ & $\begin{array}{c}\text { Multipurpose } \\
\quad \mathrm{N}=60\end{array}$ & $\begin{array}{c}\text { Producers } \\
\mathrm{N}=7\end{array}$ & $\begin{array}{c}\text { Consumer } \\
\mathrm{N}=27\end{array}$ & $\begin{array}{c}\text { Marketing } \\
\mathrm{N}=7\end{array}$ & $\begin{array}{l}\text { Pooled } \\
\mathrm{N}=101\end{array}$ & Pooled $\mathrm{N}=109$ \\
\hline $\begin{array}{c}\text { Poverty Headcount } \\
\qquad\left(\mathbf{H}_{0}\right)\end{array}$ & 0.15 & 0.29 & 0.19 & 0.14 & 0.17 & 0.220 \\
\hline $\begin{array}{c}\text { Intensity of } \\
\text { Deprivation (A) }\end{array}$ & 0.40 & 0.58 & 0.41 & 0.30 & 0.43 & 0.507 \\
\hline Poverty Index $\left(\mathrm{M}_{0}\right)$ & 0.06 & 0.14 & 0.08 & 0.05 & 0.08 & 0.112 \\
\hline
\end{tabular}

Source: Author's field survey data analysis result, 2017.

\section{f. Impact of cooperative membership on multidimensional poverty}

Mean difference test on the multidimensional poverty status of Cooperator and Noncooperator poultry farmers

Table 7 shows the estimate of the mean difference test, on the multidimensional poverty status of Cooperator and Noncooperator poultry farmers. The result reveals that the multidimensional poverty status (deprivations) of the Noncooperators is significantly higher than that of the Cooperators by 0.095 , significant at $1 \%$ level, implying that Cooperator poultry farmers are better off than their Noncooperator Counterparts. This is in consonance with the findings of Teklehaimanot A. et al., (2016).

It is however worth noting that the obtained differences in the outcome means between the Cooperators and Noncooperators poultry farmers may not be totally linked to their cooperative membership status, owing to the menace posed by self-selection and non-compliance (Heckman and Vytlacil, 2005; Imbens and Angrist, 1994). This study thus adopts the Treatment Effect analysis which can provide a robust and consistent estimates of the impact of cooperative membership on multidimensional poverty among poultry farmers. 
International Journal of Business Management and Economic Review

Vol. 3, No. 02; 2020

ISSN: 2581-4664

Table 7: Estimates of mean difference in the multidimensional poverty status of Cooperative and Noncooperative poultry farmers

\begin{tabular}{|lcccc|}
\hline \multicolumn{1}{|c}{ Parameter } & Cooperators & Noncooperators & Pooled & Difference Test \\
\hline Mean & 0.411 & 0.507 & $0.468(0.019)$ & $0.095^{* * *}$ \\
& $(0.017)$ & $(0.029)$ & & $(0.037)$ \\
Std.dev & 0.071 & 0.140 & 0.125 & \\
Min & 0.333 & 0.333 & 0.333 & \\
Max & 0.7777 & 0.555 & 0.7777 & $\mathbf{P = 0 . 0 1 4 2}$ \\
\hline
\end{tabular}

Source: Field Survey data analysis, 2017. Significance level **P $\leq 0.05, * * * \mathrm{P} \leq 0.01$, Robust standard error of mean parenthesized

\section{g. Econometric analysis on the impact of cooperative membership on the multidimensional poverty status}

To estimate the impact of cooperative membership on the poverty status of poultry farmers, this study adopts the treatment effect which provides a robust but consistent estimate while correcting for self-selection and noncompliance (bias) menaces as adopted by Adenuga et al. (2016).

\section{Results on covariates matching between the treatment and control groups}

One of the important conditional assumptions to be satisfied before using the treatment effect estimators is the overlap assumption which states that, each individual has a positive probability of receiving the treatment at each level. The overlap plots which provides a visual inspection of the density distribution helps to shows the estimated density distribution of the probability of receiving a given treatment at each treatment level. There is evidence that the overlap assumption is violated when an estimated density has too much mass around the region of 0 or 1 while the estimated densities will have relatively little mass in the regions in which they overlap. See Busso et al., (2011) and STATA, (2013). The overlap assumption is however satisfied when there is a chance of seeing observations in both the control and the treatment groups at each combination of covariate values. When the overlap assumption is violated, the estimates obtained becomes weak hence, reliable predictions or forecasting cannot be made with such.

Fig. 2 and Fig. 3 shows the estimated density of the predicted probabilities that a Noncooperator is a Cooperator and vice versa. From the plot, the estimated densities have most of their respective masses in regions in which they overlap also, the plot does not indicates too much probability mass around 0 or 1 hence, the overlap assumption is not violated. This is presented in fig. 2 while Fig. 3 shows homogeneity of covariates between the control and treatment groups, and the plot obtained shows minimum variations in the observed characteristics, indicating a good matching quality. 
Vol. 3, No. 02; 2020

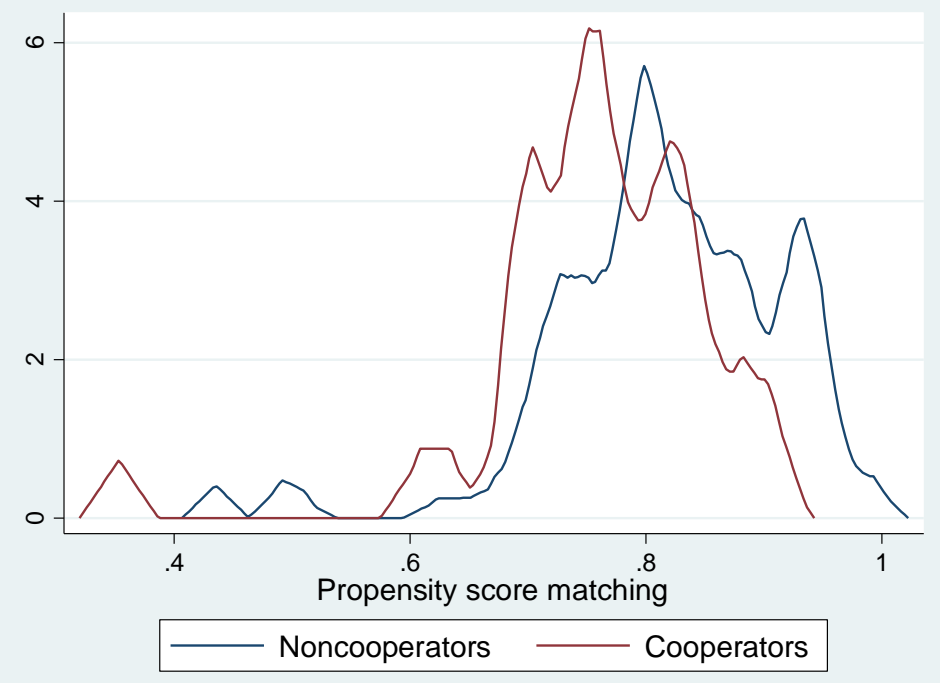

Fig 2. Propensity score distribution for overlap assumption.

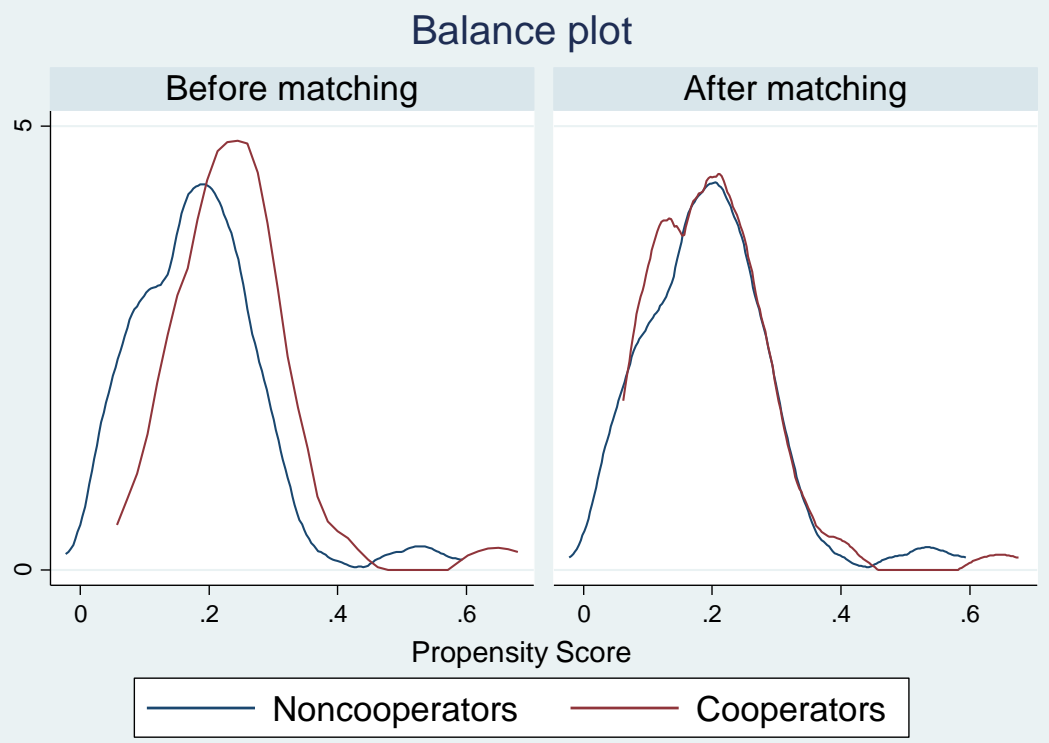

Fig 3. Before and after Propensity score matching balance plots.

The result of analysis on impact of cooperative membership on the multidimensional poverty of poultry farming households is shown in table 8 . It is important to make it clear here that table 8 contains the result of analysis on the homogeneous impact of cooperative membership among the population of poultry farmers and that on the heterogeneous impacts of each cooperative societies on the multidimensional poverty status of poultry farmers in the study area, and this involves an 


\section{International Journal of Business Management and Economic Review}

Vol. 3, No. 02; 2020

ISSN: 2581-4664

algorithm of three robust treatment effect estimators which precludes; propensity score matching (PSM), inverse probability weight (IPW) and nearest neighbour matching (NNM).

The result of the Average Treatment Effect (ATE) analysis on impact of cooperative membership on poverty status of poultry farming households in the study area shows that Cooperative membership has a likelihood of reducing multidimensional poverty by $-0.06,-0.03$, and -0.04 as respectively obtained from the PSM, IPW, and NNM estimators, significant at $10 \%$, $1 \%$ and 5\% significance levels respectively while the result of the average treatment effect on the treated (ATET) also shows negative coefficients implying a likelihood that the poverty status of a Cooperator poultry farming household in the study area is on the average reduced by -0.09 , and 0.04 , as respectively obtained from the PSM, and IPW estimators and significant at $10 \%$, and $5 \%$ significance levels respectively. This shows that cooperative membership have a significant negative impact on the poverty status of both Cooperator and Noncooperator poultry farmer in the study area. This is in consonance with the findings of Ellen Verhofstadt and Maertens (2014).

On the heterogeneous impact of the respective cooperative societies on multidimensional poverty of poultry farming households, ATE estimate shows that multipurpose cooperative have a negative impact on the multidimensional poverty with a negative coefficients of -0.03 , and -0.08 respectively from the PSM, and IPW estimators. This was found to be significant at $1 \%$, and $10 \%$ significance levels respectively while the ATET estimates also shows a negative impact of multipurpose cooperatives on the poverty status of its poultry farmer members with a negative coefficient of -0.08 obtained from the IPW estimator, significant at $5 \%$ significance level.

Regarding the producers cooperatives, the ATE estimate result show its negative impact on the multidimensional poverty of poultry farming households in the study area with a negative coefficient of -0.04 obtained from the PSM estimator, implying that producer cooperatives on the average has a likelihood of reducing multidimensional poverty among poultry farming households by -0.04 where only the PSM estimator gave a significant estimate at $1 \%$ significance level.

Furthermore, the ATET estimates show a negative impact of marketing cooperative on the multidimensional poverty status of its poultry farmer members with the obtained negative coefficients of -0.10 and -0.06 respectively from the PSM and IPW estimators. This is found to be significant at $5 \%$ and $1 \%$ level respectively.

Also, the ATET estimate result however show a significant positive relationship on impact of consumers cooperatives on the poverty status of its member poultry farming households in the study area with a positive coefficient of 0.12 from the PSM estimators significant at $5 \%$ level while the ATE estimate show no significant impact on poverty status among the heterogeneous population of poultry farming households in the study area.

Table 8: Impact of cooperative membership on the multidimensional poverty status of poultry farmers in the study area. 


\section{International Journal of Business Management and Economic Review}

Vol. 3, No. 02; 2020

ISSN: 2581-4664

\begin{tabular}{|c|c|c|c|c|}
\hline \multirow{2}{*}{ Treatments } & \multirow{2}{*}{ Estimates } & \multicolumn{3}{|c|}{ Treatment effect estimators } \\
\hline & & $\begin{array}{l}\text { Propensity Score } \\
\text { Matching (PSM) }\end{array}$ & $\begin{array}{l}\text { Inverse probability } \\
\text { weight (IPW) }\end{array}$ & $\begin{array}{l}1 \text { Nearest neighbour } \\
\text { matching (NNM) }\end{array}$ \\
\hline \multicolumn{5}{|l|}{ Cooperative Membership } \\
\hline & ATE & $-0.06 * * *$ & $-0.03 *$ & $-0.04 * *$ \\
\hline & & $(0.02)$ & $(0.02)$ & $(0.02)$ \\
\hline & ATET & $-0.09 * * *$ & $-0.04 * *$ & -0.03 \\
\hline & & $(0.03)$ & $(0.02)$ & $(0.03)$ \\
\hline \multirow[t]{4}{*}{ Multipurpose Cooperatives } & ATE & $-0.03^{*}$ & $-0.08 * * *$ & $-0.08 * * *$ \\
\hline & & $(0.02)$ & $(0.02)$ & $(0.02)$ \\
\hline & ATET & 0.02 & $-0.08 * *$ & -0.04 \\
\hline & & $(0.03)$ & $(0.04)$ & $(0.04)$ \\
\hline \multirow[t]{4}{*}{ Producers Cooperatives } & ATE & $-0.04 *$ & -0.03 & -0.05 \\
\hline & & $(0.02)$ & $(0.02)$ & $(0.07)$ \\
\hline & ATET & 0.04 & -0.02 & -0.01 \\
\hline & & $(0.06)$ & $(0.06)$ & $(0.05)$ \\
\hline \multirow[t]{4}{*}{ Marketers Cooperatives } & ATE & 0.01 & 0.03 & 0.02 \\
\hline & & $(0.07)$ & $(0.09)$ & $(0.07)$ \\
\hline & ATET & $-0.10 * *$ & $-0.06^{*}$ & -0.05 \\
\hline & & $(0.04)$ & $(0.05)$ & $(0.11)$ \\
\hline \multirow[t]{4}{*}{ Consumers Cooperatives } & ATE & 0.02 & -0.06 & 0.02 \\
\hline & & $(0.03)$ & $(0.05)$ & $(0.05)$ \\
\hline & ATET & $-0.12 * *$ & -0.01 & 0.04 \\
\hline & & $(0.06)$ & $(0.04)$ & $(0.04)$ \\
\hline
\end{tabular}

Source: Author's field survey data analysis result, 2017 . ${ }^{* * *} \mathrm{P} \leq 0.01,{ }^{* *} \mathrm{P} \leq 0.05,{ }^{*} \mathrm{P} \leq 0.10$ Robust standard errors parenthesized.

\section{CONCLUSIONS AND RECOMMENDATIONS}

This study aimed to evaluate the impact of cooperative membership on the multidimensional poverty status of poultry farmers in south west Nigeria. Result shows that the poultry farmers are still within their productive age from the obtained mean age of 47 years. The mean age of the Cooperator poultry farmers ( 49 years) was found to be significantly higher than their Noncooperator counterparts (45 years). Literacy level was found to be high as their pooled mean years of formal education is 18 years while merely $7 \%$ are deprived in basic school enrolment. However, about $26 \%$ of the poultry farming households lack access to quality healthcare. When the poverty line is set at At " $\mathrm{k}=3$ "; about $20 \%$ are multidimensionally poor in which the incidence and average intensities of deprivation of Noncooperators is higher $(22 \% ; 51 \%)$ than the Cooperators category (17\%: 38\%). The Multidimensional poverty index of the Noncooperators (0.112) is higher that the Cooperators $(0.065)$. Also, the deprivation counts of the noncooperators is significantly higher than that of the Cooperators. Besides, result from the algorithms of the ATE and ATET analysis on the homogeneous impact shows that cooperative membership reduces 


\section{International Journal of Business Management and Economic Review}

Vol. 3, No. 02; 2020

ISSN: 2581-4664

multidimensional poverty among the Cooperator and Noncooperator poultry farming households with high levels of significance while on the heterogeneous impact, multipurpose cooperatives was found to be more effective and consumer cooperatives been least effective in poverty reduction among the 4 types of cooperative societies in the study area.

Sequel to the findings from these study, it is recommended that rural electrification and access to extension agents by poultry farmers should be improved, poultry farmers should be encouraged to join cooperatives especially the multipurpose cooperative societies to ensure poverty reduction among them. Besides, Producer cooperatives should be resuscitated in order to improve its daunting efficiency. Also, efforts should be intensified towards increased access to good electricity, clean water, quality healthcare, asset acquisition, good housing, and improved sanitation, been indicators wherein poultry farming households suffers high incidence of deprivation in the study area.

\section{REFERENCES}

Adeoti Adetola I. (2014): Trend and determinants of multidimensional poverty in Rural Nigeria. Journal of development and Agricultural Economics. 6(5) pp 220-231. ISS: 2006-9774.

Adewale Adenuga, Omotesho O. A., Ojehomon V.E.T., Opeyemi Ayinde, and Aminou Arouna (2016): Adoption of Improved Rice Varieties and its Impact on Multi-Dimensional Poverty of Rice Farming Households in Nigeria. https://www.researchgate.net/publication/309780992. Retrieved: 4/29/2017.

Alkire Sabina and Foster J. (2011): "Understandings and misunderstandings of multidimensional poverty measurement", Journal of Economic Inequality 9(2): 289-314.

Amao J.O. and Awoyemi T.T. (2008). Adoption of improved cassava varieties and its welfare effect on producing households in Osogbo ADP Zone of Osun State, Nigeria, State Gene Conserve. J. Univ. Bras. Brazil 7(29):520-542.

Busso, M., J. DiNardo, and J. McCrary. (2011). New evidence on the finite sample properties of propensity score reweighting and matching estimators. Source: http://emlab.berkeley.edu/jmccrary/BDM2011.pdf. Retrieved: 18/01/2018

Cattaneo M. D., Drukker, D.M., Holland, A.D., (2013). Estimation of multivalued treatment effects under conditional independence. Journal of Statistics and data-STATA 13, 407-450.

David Drukker Jane Leber Herr Guido W. Imbens Alberto Abadie (2004) Implementing matching estimators for average treatment effects in Stata, The Stata Journal 4(3), pp. 290-311

Ellen Verhofstadt and Miet Maertens (2014): Can agricultural cooperatives reduce poverty? Heterogeneous impact of cooperative membership on farmers' welfare in Rwanda Bioeconomics Working Paper Series 014/2

Federal Department Of Livestock and Pests Control Service (FDLPC), (2007). Issues in the control of avian influenza in Nigeria. A Presentation at a Stakeholders Meeting with Poultry Association of Nigeria.

Heckman, J. and E. Vytlacil. (2005), "Structural Equations, Treatment Effects, and Econometric Policy Evaluation.” Econometrica 73:669-738.

IFAD. (2011). Rural Poverty Report: New realities, new challenges: New opportunities for tomorrow's generation. Rome: International Fund for Agricultural Development.

Imbens G. (2004). Nonparametric estimation of average treatment effects under exogeneity: A 


\section{International Journal of Business Management and Economic Review}

Vol. 3, No. 02; 2020

ISSN: 2581-4664

review, Review of Economics and Statistics. 86: 4-29.

Imbens, G. and J. M. Wooldridge, (2009). "Recent Developments in the Econometrics of Program Evaluation," Journal of Economic Literature, 47:1, 5-86.

Imbens, G.W., Angrist, J.D.(1994), Identication and Estimation of Local Average Treatment Effects. Econometrica 62, 467-476.

International Co-operative Alliance (ICA), International Labour Organization (ILO) (2015): A Contribution to the Post-2015 Development Debate (Policy Brief) https://www.google.com/search?q=International+Co operative+Alliance+(ICA), +International+Labour+Organization+(ILO)+(2015): +A+Contributio n+to+the+Post-2015+Development+Debate $+($ Policy + Brief $) \& i e=u t f-8 \& o e=u t f-8 \&$ client $=$ firefoxb\&gfe_rd=cr\&ei=-T0EWa_OL4aDaI_Sm-AB Retrieved:4/29/2017.

Jerumeh T. R. and Salman K. K. (2016), An Evaluation of the Poverty Situation of Farming Households in Selected Areas in Ibadan, Oyo state. Academia Journal of Agricultural Research 4(3): 123-133, ISSN: 2315-7739.

Living standard Measurement Study (LSM), Food and Agriculture Organization (FAO), World Bank, (2016); Measuring the Role of Livestock in the Household Economy, A Guidebook for Designing Household Survey Questionnaires

Mendola, M. (2007). Agricultural technology adoption and poverty reduction: A propensity score matching analysis for rural Bangladesh. Food Policy, 32 (3), 372-93.

Ministry Of Agriculture \& National Resources (2012), MANR Annual Report.

National Bureau of Statistics (2015): GDP Report, www.nigerianstat.gov.ng/report/371 retrieved 4/27/2017.

National Bureau of Statistics (NBS, 2014). Social Statistics in Nigeria. Federal Republic of Nigeria.

National Bureau of Statistics-NBS (2012). Poverty profile report of Nigeria. Federal Government of Nigeria, Abuja.

Oyekale, T. O. Okunmadewa, F. Y., Omonona B. T. and O.A. Oni (2006). Fuzzy set approach to Multidimensional poverty Decomposition in rural Nigeria. http://globelics2009dakar.merit.unu.edu/papers/1235327890.pdf Retrieved: 12/15/2017.

PAN. Poultry association of Nigeria, Oyo state chapter. Nigeria.

Rahman, S. (1999). Impact of technological change on income distribution and poverty in Bangladesh agriculture: An empirical analysis. Journal of International Development,11 (7),93555.

Robinson, T.P., Thornton, P.K., Franceschini, G., Kruska, R.L., Chiozza, F., Notenbaert, A., Cecchi, G., Herrero, M., Epprecht, M., Fritz, W., You, L., Conchedda, G., \& See, L. (2011). Global Livestock Production Systems. Rome: Food and Agriculture Organization of the United Nations; Nairobi: International Livestock Research Institute.

Rosenbaum, P. R. (2002). Observational Studies, 2nd Edition. Springer Verlag, New York.

Rosenbaum, P.R. and Rubin, D.B. (1983). The central role of the propensity score in observational studies for causal effects. Biometrika, 70(1), 41-55.

Rubin, D. B. (1973a). Matching to remove bias in observational studies. Biometrics 29, 159184.

Sabina Alkire, Bouba Housseini, Christoph Jindra, Gisela Robles, Yangyang Shen \& Ana Vaz, (2016) Multidimensional Poverty Index (MPI) 10 October 2016, OPHI Seminar Series, Oxford 
Vol. 3, No. 02; 2020

ISSN: 2581-4664

Poverty and Human Development Initiative, Pg.5.

Statistics and data. STATA, (2013). https://www.stata.com/manuals13/teteffectsoverlap.pdf. Retrieved: 18/01/2018

Teklehaimanot. A, Ram. b, Padaria R.N., Mathur V.C.,Mahajan V.K. and Vijayaragavan. K (2016). Impact of marketing cooperative societies in enhancing rural livelihood in India. quebec international summit of cooperatives.

United Nations (2015): Sustainable development knowledge platform https://sustainabledevelopment.un.org/post2015/summit. Retrieved: 14/06/2017.

World Bank (2015): Ending Poverty and Sharing Prosperity. Global Monitoring Report 2014/2015. ISBN: 978-1-4648-0337-6.

World Bank (2016) Poverty and Shared prosperity series, taking on inequality. Global Monitoring Report. ISBN: 978-1-4648-0979-83. 